ADVERSE DRUG REACTION

\title{
Genital condylomata in a patient receiving infliximab for Crohn's disease
}

\section{A Somasekar, R Alcolado}

Postgrad Med J 2004;80:358-359. doi: 10.1136/pgmj.2003.009332

Infliximab is a monoclonal antibody against tumour necrosis factor-alpha. Recent studies have shown that it is effective in treating patients with refractory Crohn's disease and in those with Crohn's fistulae. Though this drug is found to be safe in clinical trials, sporadic reports of serious complications have been recorded in the literature. The case of a patient who developed profuse genital warts after infliximab treatment is reported. The literature is reviewed and information is presented on side effects and complications as a result of infliximab therapy.

nfliximab, a monoclonal antibody directed against tumour necrosis factor-alpha (TNF- $\alpha$ ), is increasingly being used in the treatment of Crohn's disease. It is generally considered to be a safe drug with only minor side effects; however, sporadic reports of severe complications have been recorded in the literature. We present the case report of a patient who developed a previously unreported complication.

\section{CASE REPORT}

A 23 year old man was referred to us in September 2000 with diarrhoea and weight loss. Subsequent tests confirmed the diagnosis of Crohn's disease of the terminal ileum and colon. He was initially managed on oral steroid therapy and later azathioprine was added to control symptoms. As the disease continued to be refractory, we started a course of treatment with infliximab. After two doses of infliximab at the interval of a week, he showed improvement in his gastrointestinal symptoms, however, he developed profuse warts on his penis and perianal region. He had no history of a similar problem. Further treatment was withheld and he was referred to the genitourinary medicine department for assessment. Screening for sexually transmitted disease was negative. A diagnosis of genital condylomata acuminata was made and he was started on cryotherapy with liquid nitrogen, after which he showed rapid improvement. He was cured of genital warts on follow up, and continues to take oral steroids and azathioprine.

\section{DISCUSSION}

Crohn's disease is a chronic inflammatory disorder of the gastrointestinal tract. Common clinical manifestations include abdominal pain, diarrhoea, and weight loss. Complications of the disease range from varying degrees of perianal disease to more serious problems such as bowel strictures and fistulation between bowel loops and/or bladder and enterocutaneous fistulae.

The pathogenesis of Crohn's disease is not fully understood. Over-expression of local immune response mechanisms in the gut wall in response to common antigens associated with the gut is considered to be the main cause. ${ }^{1}$
As a result, proinflammatory processes are activated resulting in the pathological changes.

The mainstay of treatment in Crohn's disease has been steroids and disease modifying treatment in the form of immunosuppressives. However, response rates vary and side effects can be severe. ${ }^{2}$

Infliximab is a monoclonal antibody directed against the proinflammatory cytokine, TNF- $\alpha$. Recent studies have indicated that infliximab is effective in treating Crohn's disease refractory to other drugs, and in those with fistulae. ${ }^{34}$ Various mechanisms of action of infliximab have been proposed. Some studies suggest that it induces apoptosis of T lymphocytes and monocytes, ${ }^{56}$ while others indicate that it curbs the production of cytokines by the mononuclear cells in the lamina propria of the gut. ${ }^{7}$

The drug has generally been found to be safe when used in clinical trials and frequently observed side effects are minor such as headache, nausea, and upper respiratory infection. ${ }^{8}$ Sporadic serious complications have been reported and include delayed hypersensitivity reactions, aseptic meningitis, and necrotising fasciitis. ${ }^{9-11}$ Episodic treatment with infliximab for Crohn's disease in adults, especially a distant second infusion, has been suggested as a risk factor for delayed hypersensitivity reactions. ${ }^{12}$ Other side effects reported include the development/reactivation of tuberculosis ${ }^{13}$ and development of antibodies to double stranded DNA in a small percentage of patients. ${ }^{8}$ There have been no reports, however, of a true lupus syndrome or other autoimmune disorders. ${ }^{8}$

Immunosuppressive drugs, in general, can lead to opportunistic viral and other infections. Though there is no definite evidence of systemic immunosuppression in patients on infliximab, the reported instances of tuberculosis reactivation and necrotising fasciitis indicate that there might be some effect on cell mediated immunity. It may, therefore, be appropriate to treat any active infection before starting infliximab. Molluscum contagiosum, an infection caused by a pox virus, has also been reported as a result of TNF- $\alpha$ antibody treatment. ${ }^{14}$

Condylomata acuminata are caused by infection with the human papilloma virus. Most warts are caused by human papilloma virus types 6 or $11 .{ }^{15}$ Genital condylomata are commonly transmitted by sexual contact. Immunosuppressive treatment, as in transplant patients, can lead to a flare up of this condition. ${ }^{16}$ However, rapid development of condylomata as a result of infliximab treatment has not been reported before. We have since contacted the drug manufacturer regarding this case and they do not have any reports of similar side effects. It is possible that our patient had harboured a subclinical infection with the virus, which manifested after treatment with infliximab. However, we acknowledge that there is no definite way of proving this cause based on one report. It is possible that steroid treatment could have contributed to some extent, though the patient had been on high dose steroid treatment frequently in the past, with no similar effects. 
We therefore conclude that patients who are due to receive infliximab should be screened for active infection with human papilloma virus and must be treated appropriately. Patients must also be warned of the possibility of development/aggravation of anogenital warts while on infliximab therapy.

\section{Authors' affiliations}

A Somasekar, R Alcolado, Department of Gastroenterology, Royal Glamorgan Hospital, Llantrisant, UK

Correspondence to: Dr R Alcolado, Royal Glamorgan Hospital, Llantrisant CF72 8XR, Wales, UK; ruthalcolado@btinternet.com

Submitted 13 May 2003

Accepted 4 August 2003

\section{REFERENCES}

1 Hodgson HJ. Pathogenesis of Crohn's disease. Baillieres Clin Gastroenterol 1998; 12:1-17.

2 Stein RB, Hanauer SB. Comparative tolerability of treatments for inflammatory bowel disease. Drug Saf 2000;23:429-48.

3 D'Haens GR. Infliximab (Remicade), a new biological treatment for Crohn's disease. Ital J Gastroenterol Hepatol 1999;31:519-20.

4 Present DH, Rutgeerts $P$, Targan S, et al. Infliximab for the treatment of fistulas in patients with Crohn's disease. N Engl J Med 1999;340:1398-405.
5 ten Hove T, van Monffrans C, Peppelenbosch MP, et al. Infliximab treatment induces apoptosis of lamina propria T lymphocytes in Crohn's disease. Gut 2002;50:206-11

6 Lugering A, Schmidt M, Lugering $N$, et al. Infliximab induces apoptosis in monocytes from patients with chronic active Crohn's disease by using a caspase-dependent pathway. Gastroenterology 2001;121:1145-57.

7 Cornillie F, Shealy D, D'Haens G, et al. Infliximab induces potent antiinflammatory and local immunomodulatory activity but no systemic immune suppression in patients with Crohn's disease. Aliment Pharmacol Ther $2001 ; 15: 463-73$

8 Hanaver SB. Review article: safety of infliximab in clinical trials. Aliment Pharmacol Ther 1999;13(suppl 4): 16-22.

9 Riegert-Johnson DL, Godfrey JA, Myers JL, et al. Delayed hypersensitivity reaction and acute respiratory distress syndrome following infliximab infusion. Inflamm Bowel Dis 2002;8:186-91.

10 Marotte $\mathbf{H}$, Charrin JE, Miossec P. Infliximab-induced aseptic meningitis. Lancet 2001;358:1784.

11 Chan AT, Cleeve V, Daymond TJ. Necrotising fasciitis in a patient receiving infliximab for rheumatoid arthritis. Postgrad Med J 2002;78:47-8.

12 Kugathasan S, Levy MB, Saeian K, et al. Infliximab retreatment in adults and children with Crohn's disease: risk factors for the development of delayed severe systemic reaction. Am J Gastroenterol 2002;97:1408-14.

13 Keane J, Gershon S, Wise RP, et al. Tuberculosis associated with infliximab, a tumor necrosis factor alpha-neutralizing agent. N Engl J Med 2001;345:1098-104.

14 Cursiefen C, Grunke M, Dechant C, et al. Multiple bilateral eyelid molluscum contagiosum lesions associated with TNF-alpha antibody and methotrexate therapy. Am J Ophthalmol 2002;134:270-1.

15 Handsfield $\mathrm{HH}$. Clinical presentation and natural course of anogenital warts. Am J Med 1997; 102(5A): 16-20.

16 Daneshpouy M, Socie G, Clavel C, et al. Human papilloma virus infection and anogenital condyloma in bone marrow transplant recipients. Transplantation 2001;71:167-9. 